\title{
Herpes Zoster and Motor Involvement- Report of 2 Cases
}

\author{
Authors \\ Dr Sujaya Manvi ${ }^{1}$, Dr Rajni Sharma ${ }^{2}$ \\ ${ }^{1}$ Dermatologist, Civil Hospital Palampur, District Kangra, Himachal Pradesh \\ ${ }^{2}$ Dermatologist, Civil Hospital Solan, District Solan, Himachal Pradesh \\ Email:dr.rajni07@gmail.com, Contact No- 7807078993 \\ Corresponding Author \\ Dr Sujaya Manvi \\ Dermatologist, Civil Hospital Palampur, District Kangra, Himachal Pradesh \\ Email: drsujaya23@gmail.com, Contact No- 9418028669
}

\begin{abstract}
Herpes zoster caused by reactivation of varicella zoster virus is a common neurocutaneous viral infection. Motor involvement generally involves cranial nerves but motor palsies of spinal roots due to herpes zoster are also rarely recorded. We have come across two cases of motor paresis following herpes zoster one of which resolved after treatment. It is likely that if patients with herpes zoster are examined carefully, motor signs would be found more frequently.
\end{abstract}

Keywords: Varicella zoster, motor weakness, anterior horn cells.

\section{Introduction}

Herpes zoster caused by reactivation of varicella zoster virus is a common neurocutaneous viral infection. It is characterized clinically by radicular pain and vesicular cutaneous eruptions in dermatomal distribution. Though principally a disease of sensory ganglia, motor involvement is reported rarely ${ }^{1}$. Motor involvement generally involves cranial nerves but motor palsies of spinal roots due to herpes zoster are also occasionally recorded. Here we report two cases of post herpetic spinal segment paralysis.

\section{Case-1}

A 62-year-old male presented with shooting pain on the left flank off and on along with a sensation of heaviness over the left lower abdomen. There was history of fluid filled blisters over the back 7 months ago. On examination, there were coalased hyperpigmented macules over the left lumbar region. There was asymmetry of the abdomen along with sagging of the abdominal wall on the left side below the umblical region. No lump was palpable and cough impulse was negative. Sensory examination was normal. The patient was put on gabapentin for post herpetic neuralgia. He was lost to follow-up. 


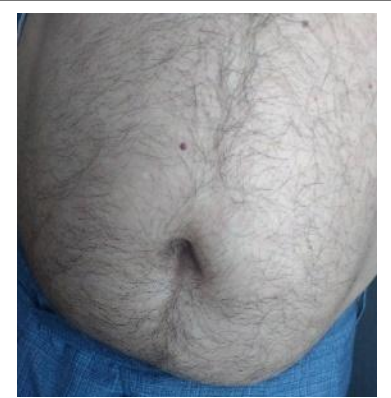

Figure 1 Showing Abdominal Muscle Laxity

\section{Case-2}

A 53-year-old female presented with coalesced fluid filled vesicles over the left lumbar region arranged along a segmental distribution of 4 days duration. On examination, there were erosions and crusting at few places. The onset of the lesions was associated with shooting pain radiating to the groin along with burning sensation. There was asymmetry of the abdomen along with sagging of the abdominal wall on the left side and hyperesthesia along the distribution of the lesions. The patient was put on valacyclovir $1000 \mathrm{mg}$ tds, NSAIDS and topical antibiotic for 7 days. On follow-up, the lesions had crusted and abdominal asymmetry had subsided.

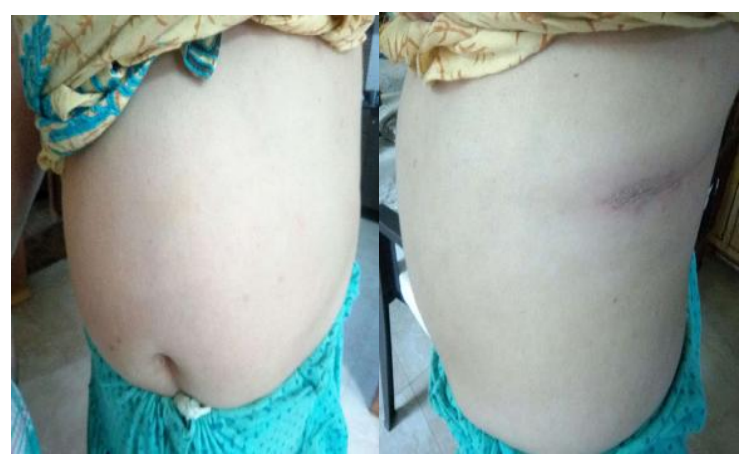

Figure 2 showing abdominal muscle laxity with concomitant skin lesions.

\section{Discussion}

Herpes zoster or shingles is a painful eruption of a unilateral rashcaused by the varicella zoster virus. Varicella zoster virus usually persists asymptomatically in the dorsal root ganglia of the person who has had chickenpox. It reactivates from its dormant state in about $25 \%$ cases and travels along the sensory nerve fibers to cause vesicular lesions in the dermatome supplied by that nerve. Herpes zoster is more common in people with diminished cell mediated immunity. This includes elderly people, patients with lymphoma, those receiving chemotherapy or steroids, and people with HIV. In contrast to herpes simplex, precise triggers for herpes zoster are not known ${ }^{2}$. Motor neuropathy is an uncommon complication that may follow an outbreak of herpes zoster. The first case of motor involvement due to herpes zoster was reported in 1866 by William Broadbent $^{3}$. It mostly involves the cranial nerves ${ }^{4}$. Motor palsy due to spinal nerve involvement is rare. Segmental paralysis of herpes zoster is a focal motor paralysis that occurs in a myotome corresponding to the dermatome having a skin eruption, which occurs in approximately $0.5-5 \%$ of all herpes zoster cases ${ }^{1,4}$. The motor weakness usually follows the pain and the eruption by a few days to a few weeks but occasionally precedes or accompanies them. The affected segment is usually but not always the same. Complete recovery is expected in $55 \%$ and significant improvement in a further $30 \%$. In a series involving 1432 cases of herpes zoster, Akiyama reported, $11(0.8 \%)$ cases developing lower motor neuron paralysis and all of them were above 60 years of age ${ }^{1}$. Massaerelli ${ }^{5}$ reviewed the records of 60 hospitalized patients with herpes zoster to study the clinical features of motor involvement and found three cases of upper extremity paralysis and one of the lower extremity. In addition, a rare case of diaphragmatic paralysis associated with cervical zoster was found.Pathy ${ }^{6}$ observed 14 subjects over a period of five years out of which nine had flaccid limb paralysis. Recovery was not always complete and occurred over a period of nine weeks to four years. Motor paralysis occurring in herpes zoster can be categorized into segmental and non-segmental paresis depending on whether the dermatome of the skin eruption matches relevant segment of the motor nervous system. Motor involvement occurs through the following several ways. First, it can be caused by 


\section{JMSCR VoI||05||Issue||12||Page 32176-32178||December}

the infection that first begins in spinal dorsal root ganglion and then progresses to anterior horn through motor nerve root. This type of paralysis usually occurs in first few weeks after onset of skin rash but occasionally precedes or accompany them. Second, it can be a result of segmental myelitis. Third, it can be caused by secondary degeneration of affected motor nerve root. Fourth, it can be caused by inflammation of both sensory and motor nervous system ${ }^{7}$.Hannapa et $\mathrm{al}^{8}$ noted in a sample of 40 patients with acute herpes zoster of varying severity, an abnormal electromyogram (EMG) (fibrillation, positive waves, high-frequency discharges) was found in 21 (53\%), suggesting extension of inflammation to the anterior horn and/or anterior motor roots. In the majority of patients these changes were not confined to the segment invaded by the rash but were widespread, extending several segments cranially and caudally and both ipsi- and contralaterally. In 5 (13\%) patients these changes became more extensive on repeat EMG over a period of months. However, no association between severity of rash, pain, post herpetic neuralgia and EMG changes was noted. They concluded that subclinical motor involvement is relatively common in herpes zoster, may last for months, and is easily detectable by EMG.

Often the pain does not allow adequate examination of the patient and this may be the reason why motor paralysis is not often reported in patients with herpes zoster. It is likely that if patients with herpes zoster are examined carefully, motor signs would be found more frequently.

\section{References}

1. Das AL, Ramadasan P, Patra AK. Post Herpetic Spinal Segmental Paralysis. MJAFI 2007; 63: 195-96.

2. Wareham DW, Breuer J. Herpes zoster. BMJ; 334(7605): 1211-15.

3. Greenberg J. Herpes Zoster with Motor Involvement.JAMA 1970;212(2):322.
4. Sterling JC. Virus Infections. In: Burns T, Breathnach S, Cox N, Griffiths C, editors. Rook's Textbook of Dermatology. $8^{\text {th }}$ ed. Blackwell Publishing: Oxford; 2010.p. 33.2233.23.

5. Massarelli JJ. Motor Involvement in Herpes Zoster.Ann Intern Med. 1968;68(5):1175.

6. Pathy MS. Motor complications of herpes zoster. Age and Ageing 1979; 8(2): 75-80.

7. Haanpää M, Häkkinen V, Nurmikko T.Motor involvement in acute herpes zoster. Muscle Nerve. 1997;20(11):1433-8. 